\title{
Catalytic fast pyrolysis of corn stover in a fluidized bed heated by hot flue gas: Physicochemical properties of bio-oil and its application
}

\author{
Yang Wen ${ }^{1}$, Fu Peng ${ }^{3,4}$, Yi Weiming ${ }^{2,4 *}$ \\ (1. College of Engineering, Shenyang Agricultural University, Shenyang 110866, China; \\ 2. President's Office, Shandong University of Technology, Zibo 255000, Shandong, China; \\ 3. School of Agricultural and Food Engineering, Shandong University of Technology, Zibo 255000, Shandong, China; \\ 4. Shandong Research Center of Engineering and Technology for Clean Energy, Zibo 255000, Shandong, China)
}

\begin{abstract}
Fast pyrolysis of corn stover was performed at temperatures in the range of $450^{\circ} \mathrm{C}-525^{\circ} \mathrm{C}$ in a fluidized bed. The chemical composition of the bio-oil acquired was analyzed by GC/MS, and its $\mathrm{pH}$, kinetic viscosity and calorific values were determined. In the pyrolysis system used in this experiment, some improvements to former pyrolysis systems were done. Two screw feeders were used to prevent jamming the feeding system, and the condenser was equipped with some nozzles and a heat exchanger to cool quickly the cleaned hot gas into bio-oil. The results showed that the bio-oil yield increased with increasing pyrolysis temperature and then declined with a further increase in pyrolysis temperature. The highest bio-oil yield of 43.3 wt. $\%$ was obtained at $500^{\circ} \mathrm{C}$ with the dolomite as bed material. The char yield always decreased with the increase of temperature. The major chemical compounds of bio-oil included acetol, butanone, acetic acid, propionic acid, ethylene glycol, phenol, etc. Pyrolysis oil was completely immiscible in diesel, but homogeneous emulsions were obtained when mixing the pyrolysis oil, emulsifier with diesel in different ratios.
\end{abstract}

Keywords: corn stover, pyrolysis, bio-oil, fluidized bed, hot flue gas, GC/MS

DOI: $10.25165 /$ j.ijabe.20171005.2473

Citation: Yang W, Fu P, Yi W M. Catalytic fast pyrolysis of corn stover in a fluidized bed heated by hot flue gas: Physicochemical properties of bio-oil and its application. Int J Agric \& Biol Eng, 2017; 10(5): 226-233.

\section{Introduction}

Because of the global climate changes, environmental pollution and reduction of availability of fossil energy resources, there is increasing interest in biomass as a

Received date: 2017-03-28 Accepted date: 2017-08-09

Biographies: Yang Wen, $\mathrm{PhD}$ candidate, research interests: agricultural biological environment and energy engineering, Email: yangwen@sdut.edu.cn; Fu Peng, Associate Professor, research interests: biomass pyrolysis and gasification technology, Email: fupeng@sdut.edu.cn.

* Corresponding author: Yi Weiming, PhD, Professor, research interests: biomass energy. Shandong Research Center of Engineering and Technology for Clean Energy, President's Office, Shandong University of Technology, No.266 Xincun Road, Zhangdian District, Zibo 255000, Shandong Province, China. Tel/Fax: 0533-2789077, Email: yiweiming@sdut.edu.cn. renewable resource with high potential for energy production. Biomass can be converted to various forms of energy through numerous thermochemical conversion processes $^{[1,2]}$, depending upon the type of energy desired. Among the thermochemical processes, pyrolysis is a promising tool for providing bio-oil that can be used as fuel or chemical feedstock ${ }^{[3]}$.

Depending on the operating conditions, the pyrolysis process can be divided into two classes: conventional pyrolysis and fast or flash pyrolysis ${ }^{[4]}$. Conventional pyrolysis is a known technology for producing charcoal (mainly) and chemicals such as methanol and acetic $\operatorname{acid}^{[5]}$. The main goal of fast pyrolysis is to convert the biomass into a liquid. In practice, about $40 \%-75 \%$ of the biomass (on dry basis) is converted into pyrolytic oil, and about $10 \%-20 \%$ of the biomass is converted into 
$\operatorname{char}^{[6]}$. Fast pyrolysis offers a flexible and attractive way of converting biomass into a liquid, which can be easily stored, transported and handled for the production of heat, power and chemicals. In fast pyrolysis, biomass decomposes very quickly to generate mostly vapours and aerosols and some charcoal and gas. After cooling and condensation, a dark brown homogenous mobile liquid is formed which has a heating value about half that of conventional fuel oil. A high yield of liquid is obtained with most biomass feeds low in ash. Principles and practice of biomass fast pyrolysis and applications for the liquid product were reviewed by Bridgwater ${ }^{[7]}$. Bio-oil has a number of undesirable characteristics as fuel, such as thermally unstable components leading to gum formation, low heating value due to the water content and highly oxygenated compounds, a corrosive organic acid component, and phase instability with a tendency towards phase separation ${ }^{[6,7]}$.

Corn stover is one of the major agriculture biomasses produced in large quantities in developing countries. In China, nearly 1.22-1.27 million tons of corn stover as residue is produced every year $^{[8]}$. Part of these is consumed in a traditional way, such as fodder for livestock and household fuel for stoves. Until recently, the majority of corn stovers have not been used and disposed of by burning in open fields, causing environmental and public health problems. At present, China energy policies are strongly encouraging the use of corn stover for energy purposes, mainly owing to three aspects: economic and social development, elimination of wastes, and reduction of $\mathrm{CO}_{2}$ emissions ${ }^{[9]}$. In this situation, fast pyrolysis of biomass, as a promising technology, constitutes an attractive option.

Comparing the density and energy content in the corn stover with rice straw, it has been found that the density of corn stover $\left(220 \mathrm{~kg} / \mathrm{m}^{3}\right)$ is higher than the density of rice straw $\left(63.85 \mathrm{~kg} / \mathrm{m}^{3}\right)$. Furthermore, the energy content in the corn stover is $15.07 \mathrm{MJ} / \mathrm{kg}$ which is higher than the energy content of rice straw $(13.62 \mathrm{MJ} / \mathrm{kg})^{[10]}$. This clearly suggests that the bioenergy plant using corn stover will be more efficient than some straw available in the world. Fixed carbon content and the volatile fraction in corn stover are higher than many agricultural biomass $^{[11]}$. And so it can be realized that pyrolysis oil from fast pyrolysis of corn stover has higher quality. Fast pyrolysis of a large number of feedstocks, such as rice husk, rice straw, wood, cedar sawdust, coffee bean residue, sugarcane residue, cassava residue and many more, has been extensively studied ${ }^{[12-17]}$. In order to improve the quality of bio-oil, some catalytic pyrolysis tests were performed based on fixed bed reactor, and the catalyzers included red mud, HZSM-5 and metallic oxide ${ }^{[18-20]}$. However, there has been little information to produce bio-oil from fast catalytic pyrolysis of corn stover by fluidized-bed reactor. In this study, fast pyrolysis of corn stover was investigated in a fluidized-bed reactor with dolomite as catalytic bed material and the effects of pyrolysis temperature and bed material on the product distribution were analyzed. The chemical composition of the bio-oil acquired was analyzed by $\mathrm{GC} / \mathrm{MS}$, and its $\mathrm{pH}$, kinetic viscosity and calorific values were determined.

\section{Materials and methods}

\subsection{Biomass feedstock}

Corn stover was used in this study as the representatives of agricultural residues. The sample was first crushed and sieved. Fractions in the size range of $<1.0 \mathrm{~mm}$ were used in the pyrolysis experiments. The main properties of corn stover are listed in Table 1.

Table 1 Main characteristics of corn stover

\begin{tabular}{cc}
\hline Proximate analysis/wt.\% & Value \\
\hline Moisture & $6.35 \pm 0.12$ \\
Volatile matter & $74.61 \pm 0.34$ \\
Fixed carbon & $13.45 \pm 0.21$ \\
Ash & $5.59 \pm 0.17$ \\
\hline Ultimate analysis/wt.\% & \\
\hline Carbon & $48.62 \pm 0.23$ \\
Hydrogen & $5.86 \pm 0.09$ \\
Nitrogen & $0.85 \pm 0.06$ \\
Oxygen (by difference) & $44.67 \pm 0.25$ \\
Calorific value $/ \mathrm{MJ} \cdot \mathrm{kg}^{-1}$ & $17.3 \pm 0.65$ \\
\hline
\end{tabular}

\subsection{Experimental apparatus and procedure}

The fast pyrolysis experiments were performed in the fluidized-bed biomass fast pyrolysis liquefaction plant (Figure 1) located in Shandong Research Center of Engineering \& Technology for Clean Energy (Zibo, China). The experimental device mainly consists of a 
hopper, two screw feeders, an electric heater, a fluidized bed reactor, two cyclones, two condensers, an oil pump, etc. The hopper is used to contain corn stover feedstock. The two screw feeders have the same configuration and size; the first one is used to control the feeding rate and the second one operates at a relatively high speed to prevent jamming the feeding system. The fluidized bed reaction tube has a height of $2 \mathrm{~m}$ and a diameter of $70 \mathrm{~mm}$ in which the corn stovers are rapidly heated for pyrolysis. The electric heater can ensure the reactor to maintain the required temperature. The two cyclones are used to separate solid particles such as charcoal and ash from the hot gas. The condenser is equipped with some nozzles and a heat exchanger. The condenser can quickly cool the cleaned hot gas into a liquid. An oil pump is used to pump the condensed liquid from the bottom of the condenser to the nozzles on the top of the condenser. Pumping the cooled liquid back into the condenser assists in the scrubbing and condensation process. Thermocouples and pressure meters are used to monitor and control the pyrolysis system. The specification of the thermocouples is $\mathrm{K}$ Type, made from the alloy of $\mathrm{Pt}-\mathrm{Rh}$, measurement range from 0 to $815^{\circ} \mathrm{C}$ with measurement accuracy of the thermocouples of $\pm 1{ }^{\circ} \mathrm{C}$. The specification of the pressure gauges has a range from 0 to $2.5 \mathrm{MPa}$, and the measurement accuracy of the pressure gauges is $\pm 0.004 \mathrm{MPa}$.

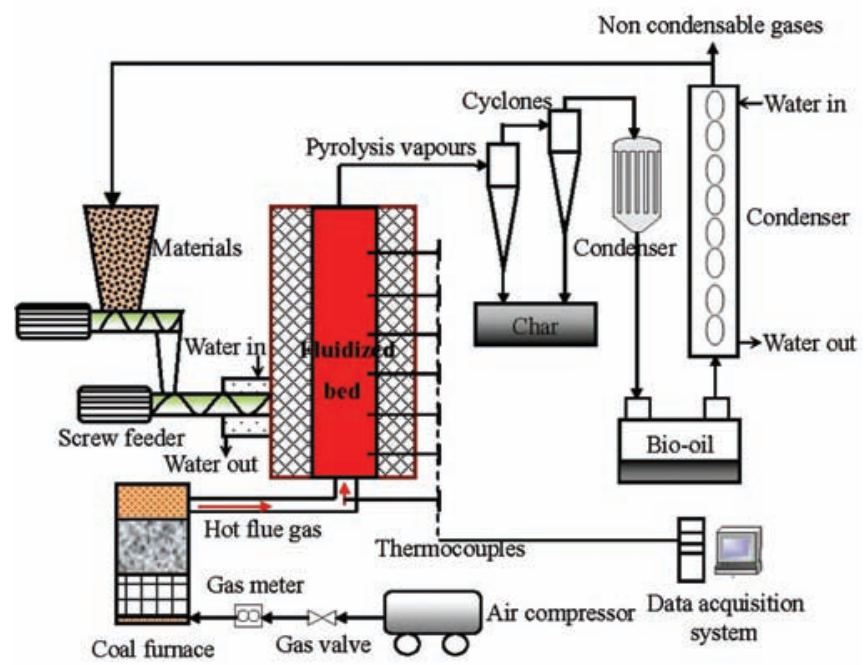

Figure 1 Experimental device of biomass pyrolysis experimental system

In the first experiment, some ethanol was put into the condenser for scrubbing the hot gas. Therefore, the liquid obtained from the condenser actually consisted of a mixture of ethanol and pyrolysis oil pyrolysed from corn stover. As ethanol has a high volatility, its concentration in the mixture would continually decrease during the experiments until the ethanol was completely gone. According to our experience, it can be considered that the mixture only consisted of the pyrolysis oil pyrolysed from corn stover if the experiment lasted for more than $10 \mathrm{~h}$. Approximately $3 \mathrm{~kg}$ of ground corn stover particles were put into the reactor. The flow rate of hot flue gas was kept $5.5 \mathrm{~m}^{3} / \mathrm{h}$, and the hot flue gas was reheated to the setting temperature by preheater. In the second condenser, the temperature was close to room temperature. After the experiment lasted for more than $10 \mathrm{~h}$, ethanol was not detected by GC-MS in the pyrolysis oil. Besides pyrolysis oil, two by-products, namely charcoal and an un-condensable gas, could also be obtained when corn stover was pyrolyzed. Corn stover was fast pyrolyzed in a fluidized-bed reactor and the pyrolysis temperature was between $450^{\circ} \mathrm{C}$ and $525^{\circ} \mathrm{C}$. The yield of pyrolysis oil could be determined from the condensed liquid. The yield of charcoal could be determined from the charcoal collected from the two cyclones. The yield of uncondensable gas could be determined from the fact that the sum of three product yields should equal $100 \%$. All the experiments with different level were conducted in triplicate and the average values were reported.

The $\mathrm{pH}$ of bio-oil was measured by a PHS-2F digital $\mathrm{pH}$ meter. Prior to the measurement, the instrument was calibrated with a liquid calibration standard of $\mathrm{pH} 7$. The calorific value was obtained using a IKA C2000 automatic isoperibol calorimeter. The bio-oil was analyzed by a Agilent 6890/5973N Gas ChromatographMass Spectrometer (GC-MS). For the GC separation, a capillary column DB-1701 $(60 \mathrm{~m} \times 0.25 \mathrm{~mm} \times 0.25 \mu \mathrm{m}$ inner diameter) was used. Carrier gas was $\mathrm{He}$ with a flow rate of $59.7 \mathrm{~mL} / \mathrm{min}$. The column oven programme was as follows: initial temperature of $40^{\circ} \mathrm{C}$ with a heating rate of $5^{\circ} \mathrm{C} / \mathrm{min}$ to $240^{\circ} \mathrm{C}$ and held during $300 \mathrm{~s}$. The mass spectrometry operating parameters: electron impact (EI) ion source at $70 \mathrm{eV}$, the scanning range of $\mathrm{m} / \mathrm{z} 12$ to 550 , ion source temperature was $150^{\circ} \mathrm{C}$, the interface temperature is $240^{\circ} \mathrm{C}$. The heating injection volume 
was $0.2 \mathrm{~L}$, and the split ratio was 60:1. The water content of bio-oil was measured by Karl-Fischer titration using a Metrohm $870 \mathrm{KF}$ Titrino Plus. The non-condensable gas was monitored by a infrared gas analyzer (GASBOARD 3100). The stability characteristics of pyrolysis oil were studied in terms of variation of viscosity over time. Viscosity measurements were done over a period of time under two different storage conditions, one stored at room temperature $\left(18^{\circ} \mathrm{C}\right)$ and the other stored at ageing temperature $\left(60^{\circ} \mathrm{C}\right)$, for each of the oil samples. The viscosity was measured according to the standard procedure (ASTM D-445-88).

\section{Results and discussion}

\subsection{Pyrolysis product distribution}

The pyrolysis product yields as a function of pyrolysis temperatures with quartz sand as bed material are present in Figure 2. The bio-oil yield increases from 31.5wt.\% to $39.6 \mathrm{wt} . \%$ with increasing pyrolysis temperature from $450^{\circ} \mathrm{C}$ to $500^{\circ} \mathrm{C}$ and then changes little with a further increase of pyrolysis temperature. The gas yield always decreases with increasing temperature until $500^{\circ} \mathrm{C}$. Afterwards, the gas yield increases with a further rise of temperature. The increase in gas yield at higher temperatures is predominately attributed to secondary cracking or reactions of pyrolysis vapors ${ }^{[21]}$. The extent of secondary reactions can be affected by pyrolysis temperature. At higher temperatures, secondary reactions in the vapor phase are much faster, leading to over-cracking of pyrolysis vapors and an increase of the gas yield. Inorganic matters as $\mathrm{K}_{2} \mathrm{O}, \mathrm{Na}_{2} \mathrm{O}, \mathrm{CaO}$ and $\mathrm{Fe}_{2} \mathrm{O}_{3}$ may play a catalytic role in tar cracking and might help to increase the gas yield ${ }^{[21]}$. The char yield always decreases with the rise of pyrolysis temperature in the range of $450^{\circ} \mathrm{C}-525^{\circ} \mathrm{C}$. The decrease in char yield with rising temperature could either be due to greater primary decomposition of raw materials at higher temperatures or through secondary decomposition of the char residue. The secondary decomposition of the char at higher temperatures may produce non-condensable gaseous products, which would also contribute to the increase in gas yield with the rise in temperature.

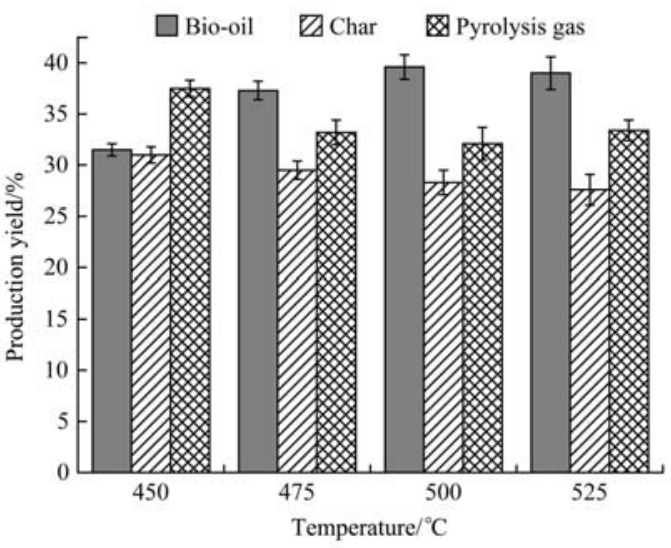

Figure 2 Product yields as a function of pyrolysis temperatures with quartz sand as bed material

The effects of pyrolysis temperature on the composition of gas products with quartz sand as bed material are displayed in Figure 3. $\mathrm{CO}_{2}, \mathrm{CO}$ and $\mathrm{CH}_{4}$ are the main gas products. The content of $\mathrm{CO}_{2}, \mathrm{CO}$ and $\mathrm{CH}_{4}$ in the pyrolysis gases accounted for more than $90 \%$. As the temperature rises, the $\mathrm{CO}$ content in the product gases increases from $29.85 \mathrm{vol} \%$ at $450^{\circ} \mathrm{C}$ to $33.95 \mathrm{vol} \%$ at $525^{\circ} \mathrm{C}$ and the $\mathrm{CH}_{4}$ content increased from $5.38 \mathrm{vol} \%$ at $450^{\circ} \mathrm{C}$ to $8.82 \mathrm{vol} \%$ at $525^{\circ} \mathrm{C}$, while the $\mathrm{CO}_{2}$ content exhibits the opposite trend. This is largely because the release of $\mathrm{CO}_{2}$ is mainly caused by the cracking and reforming of carboxyl groups which can be easily decomposed at relatively low temperatures. Furthermore, the secondary reactions of volatiles at high temperatures generate mostly $\mathrm{CO}$ and $\mathrm{CH}_{4}$ rather than $\mathrm{CO}_{2}{ }^{[22,23]}$. The heating value of pyrolysis gases increased from $6.93 \mathrm{MJ} / \mathrm{kg}$ to $9.11 \mathrm{MJ} / \mathrm{kg}$ with increasing temperatures from $450^{\circ} \mathrm{C}$ to $525^{\circ} \mathrm{C}$. The pyrolysis gases can be used as energy sources for pyrolysis processes or in other applications.

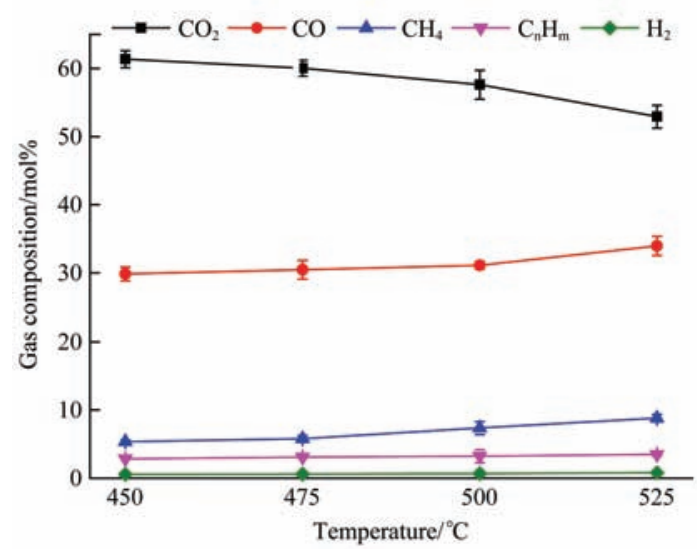

Figure 3 Effect of pyrolysis temperature on the composition of pyrolysis gases with quartz sand as bed material 
The effects of bed materials on bio-oil yield and heavy oil percentage in the whole bio-oil are shown in the Figure 4. The highest bio-oil yield of $43.3 \mathrm{wt} . \%$ is obtained at $500^{\circ} \mathrm{C}$ when dolomite is used as bed material. The heavy oil percentage in the whole bio-oil first increases and then decreases with the rise of temperature. For a given temperature higher than $450^{\circ} \mathrm{C}$, calcined dolomite gives the lowest heavy oil percentage compared with quartz sand and aluminous soil. It is well known that the formation of tar has adverse effects on bio-oil production and pyrolysis system. It usually adheres to the internal walls of the pipes and reactors and is difficult to be cleaned. Calcined dolomite is favorable for bio-oil production below $500^{\circ} \mathrm{C}$. A great quantity of $\mathrm{CaO}-\mathrm{MgO}$ complexes, which are formed via the calcination of dolomite, have a positive effect on the catalytic cracking of biomass tars, leading to the increase of bio-oil yield.
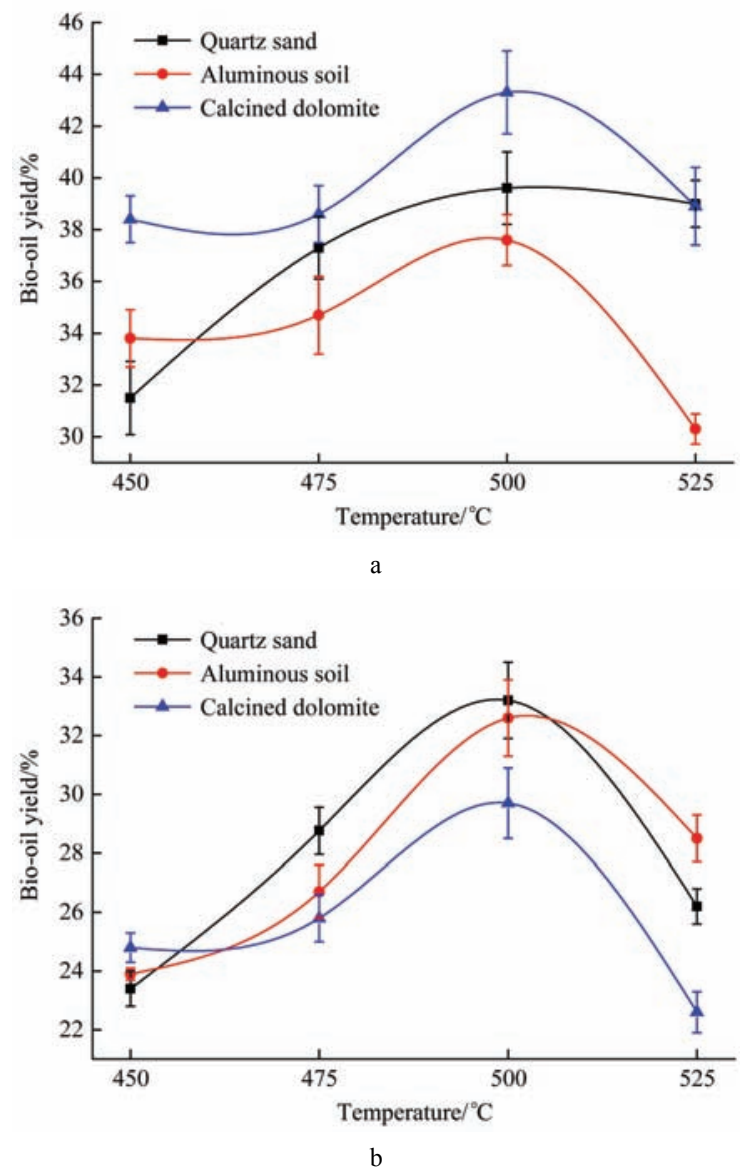

Figure 4 Effect of bed materials on (a) bio-oil yield and (b) heavy oil percentage in the whole bio-oil

\subsection{Properties and compositions of the bio-oil}

The bio-oil produced from fast pyrolysis of corn stover was a viscous and dark-brown organic liquid with a fairly strong smoky odour.
Table 2 gives the main physical properties of light bio-oil obtained from corn stover in relation to pyrolysis temperatures and bed materials. The $\mathrm{pH}$ of light oils ranged from 3.18 to 3.99 . The kinetic viscosity ranges from $5.0 \mathrm{mPa} \cdot \mathrm{s}$ to $5.9 \mathrm{mPa} \cdot \mathrm{s}$. The calorific value was very low which only ranged from $7.63 \mathrm{MJ} / \mathrm{kg}$ to $8.25 \mathrm{MJ} / \mathrm{kg}$. The viscosity of the pyrolysis oil as produced can be greatly varied depending on the temperature, feedstock, water content of the oil, amount of light ends that have been collected and the extent to which the pyrolysis oil has aged. The viscosity of pyrolysis light oil produced from corn stover was found to be around $5.5 \mathrm{mPa} \cdot \mathrm{s}$ at $18^{\circ} \mathrm{C}$. This value was much lower than many pyrolysis oils and also lower than some hydrocarbon fuels ${ }^{[24]}$. In the application of liquid as fuel, the lower the viscosity of the oil is, the easier it is to pump and to atomize and achieve finer droplets. This is the major criterion upon which the oils are aged. Since the pyrolysis oil from corn stover was lower viscous than many other pyrolysis oils and hydrocarbon fuels ${ }^{[24]}$, it was assumed that this pyrolysis oil can be used in the internal combustion engine for transportation and power generation.

Table 2 Physical properties of light oil from fast pyrolysis of

\begin{tabular}{ccccc}
\multicolumn{5}{c}{ corn stover } \\
\hline Bed material & $\begin{array}{c}\text { Temperature } \\
/{ }^{\circ} \mathrm{C}\end{array}$ & $\mathrm{pH}$ & $\begin{array}{c}\text { Kinetic viscosity } \\
/ \mathrm{mPa} \cdot \mathrm{s}\end{array}$ & $\begin{array}{c}\text { Calorific value } \\
/ \mathrm{MJ}^{-1} \mathrm{~kg}^{-1}\end{array}$ \\
\hline \multirow{5}{*}{ Quartz sand } & 450 & $3.40 \pm 0.17$ & $5.3 \pm 0.1$ & $7.68 \pm 0.12$ \\
& 475 & $3.94 \pm 0.09$ & $5.5 \pm 0.1$ & $7.89 \pm 0.15$ \\
& 500 & $3.71 \pm 0.23$ & $5.5 \pm 0.2$ & $7.73 \pm 0.23$ \\
& 525 & $3.54 \pm 0.14$ & $5.9 \pm 0.2$ & $7.79 \pm 0.18$ \\
\hline \multirow{3}{*}{ Aluminous } & 450 & $3.18 \pm 0.04$ & $5.5 \pm 0.1$ & $8.12 \pm 0.09$ \\
& 475 & $3.68 \pm 0.08$ & $5.5 \pm 0.3$ & $8.09 \pm 0.21$ \\
& 500 & $3.61 \pm 0.06$ & $5.4 \pm 0.2$ & $7.79 \pm 0.32$ \\
& 525 & $3.77 \pm 0.09$ & $5.5 \pm 0.5$ & $7.82 \pm 0.15$ \\
\hline \multirow{2}{*}{ Dolomite } & 450 & $3.29 \pm 0.12$ & $5.2 \pm 0.3$ & $8.15 \pm 0.18$ \\
& 475 & $3.99 \pm 0.06$ & $5.5 \pm 0.4$ & $7.76 \pm 0.42$ \\
& 500 & $3.74 \pm 0.13$ & $5.5 \pm 0.3$ & $8.25 \pm 0.19$ \\
& 525 & $3.56 \pm 0.15$ & $5.0 \pm 0.3$ & $7.63 \pm 0.38$ \\
\hline
\end{tabular}

When the calcined dolomite was used as bed material, the bio-oil production was highest at $500^{\circ} \mathrm{C}$, and the bio-oil was further analyzed. The properties and components of pyrolysis oil are presented in Tables 3 and 4 .

From Table 3, it could be found that: (1) The energy density of the pyrolysis oil is much higher than that of the corn stover so that it is convenient for transportation and 
utilization. (2) The oxygen content of the pyrolysis oil is high. The oxygen content of the pyrolysis oil depends on the raw material and the pyrolysis conditions. The oxygen content of the corn stover was $44.67 \mathrm{wt} . \%$ and the oxygen content of the pyrolysis oil must be higher than the oxygen content of the corn stover, because $20 \mathrm{wt} . \%-30 \mathrm{wt} . \%$ charcoal which was mainly made from carbon was produced when corn stover was fast pyrolysed. Moreover maximum yields of pyrolysis oil were obtained at temperatures in the range $450^{\circ} \mathrm{C}-550^{\circ} \mathrm{C}$ and residence times of 0.5-5 s depending on the particular process ${ }^{[7]}$ being typical conditions of fast pyrolysis. In this case the pyrolysis oil was highly oxygenated. The high oxygen content was indicative of the presence of many highly polar groups leading to high viscosities and boiling points as well as relatively poor chemical stability. As the table showed a significant fraction of the oxygen was present as water. On account of their high oxygen content and hydrophilic character it was not surprising that fast pyrolysis oils were mostly insoluble in hydrocarbon solvents. (3) The calorific value of the pyrolysis oil was $17.2 \mathrm{MJ} / \mathrm{kg}$ but the calorific value of diesel is $42.6 \mathrm{MJ} / \mathrm{kg}$, the calorific value of coal is 29.3 $\mathrm{MJ} / \mathrm{kg}$, and the calorific value of gasoline is $44.0 \mathrm{MJ} / \mathrm{kg}$. It revealed that the calorific value of the pyrolysis oil was much lower than the calorific value of fossil fuel because the oxygen content of the pyrolysis oil was high.

Table 3 Main properties of bio-oil derived from fast pyrolysis

\begin{tabular}{lc}
\multicolumn{2}{c}{ of maize stalk. } \\
\hline \multicolumn{1}{c}{ Elemental composition } & Value \\
\hline Carbon/wt.\% & $43.61 \pm 0.82$ \\
Hydrogen $/ \mathrm{wt} \%$ & $7.14 \pm 0.48$ \\
Nitrogen $/ \mathrm{wt} \%$ & $0.43 \pm 0.01$ \\
Oxygen $($ by difference $/ \mathrm{wt} \%$ & $48.90 \pm 0.98$ \\
Water content $/ \mathrm{wt} . \%$ & $23.53 \pm 0.52$ \\
Density $/ \mathrm{kg} \cdot \mathrm{m}^{-3}$ & $1220 \pm 68$ \\
Calorific value $/ \mathrm{MJ} \cdot \mathrm{kg}^{-1}$ & $17.23 \pm 0.62$ \\
$\mathrm{pH}$ & $3.2 \pm 0.2$ \\
\hline
\end{tabular}

The main organic components of the bio-oil were identified with gas chromatography-mass spectrometry (GC/MS) technique. Figure 5 shows the total ion current chromatogram of corn stover fast pyrolysis bio-oil. It can be found that more than 100 peaks were displayed in the chromatogram. Most of the identified peaks are oxygenated compounds, which included acids, aldehydes, ketones, esters, alcohols, furanics, pyranics, anhydrosugars, phenols, etc. Since the oxygenated compounds in the bio-oil are nonpolar, it is not miscible with petroleum oil. Nevertheless, the bio-oil could be blended with petroleum fuel via emulsification. Table 4 lists the major chemical compounds in corn stover fast pyrolysis bio-oil as determined by GC/MS. The major chemical compounds includes 1-hydroxy-2-propanone, acetic acid, ethanol, 1,2-Ethanediol, 2-Methyl-2cyclopenten-1-one, benzenediol, levoglucosan, phenols, etc. The perfect identification of all the peaks is not possible due to the complex composition of biomass pyrolysis oil and the difficulties in the identification are mainly due to overlapping peaks and low signal to noise ratios.

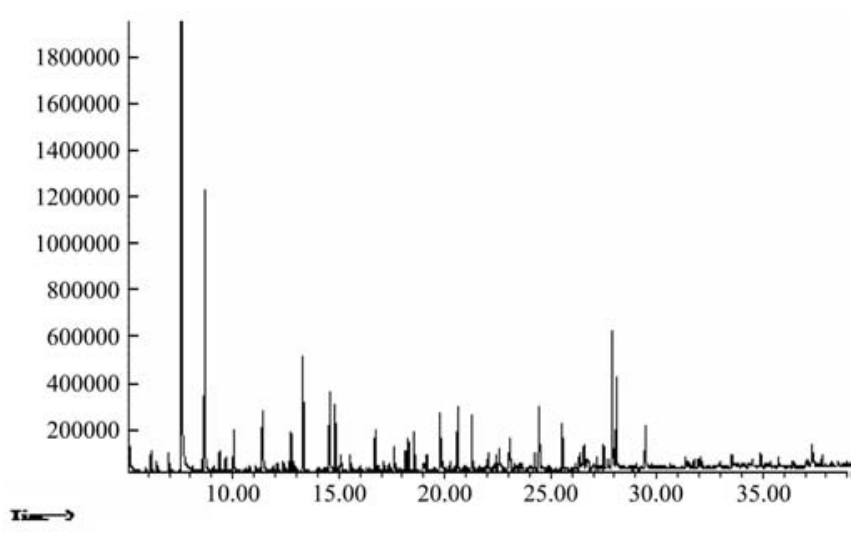

Figure 5 Total ion current chromatogram of corn stover fast pyrolysis bio-oil

Table 4 Major chemical compounds in corn stover fast pyrolysis bio-oil as determined by GC-MS

\begin{tabular}{cclc}
\hline No. & $\begin{array}{c}\text { Retention } \\
\text { time/min }\end{array}$ & \multicolumn{1}{c}{ Compound name } & Percentage \\
\hline 1 & 5.506 & Methyl Alcohol & 3.048 \\
2 & 6.403 & Propanoic acid, anhydride & 1.270 \\
3 & 7.015 & Acetaldehyde, hydroxy- & 4.316 \\
4 & 7.646 & Acetic acid & 18.853 \\
5 & 8.747 & 2-Propanone, 1-hydroxy- & 19.101 \\
6 & 1.167 & Propanoic acid & 3.086 \\
7 & 11.422 & 1-Hydroxy-2-butanone & 5.079 \\
8 & 12.775 & Propanoic acid, 2-oxo-, methyl ester & 1.772 \\
9 & 13.307 & Furfural & 3.362 \\
10 & 14.587 & 2-Furanmethanol & 4.374 \\
11 & 14.838 & 2-Propanone, 1-(acetyloxy)- & 1.709 \\
12 & 16.747 & 1,2-Cyclopentanedione & 1.341 \\
13 & 18.296 & Furan, tetrahydro-2-methyl- & 2.343 \\
14 & 18.565 & 2(5H)-Furanone & 1.303 \\
15 & 19.802 & 2-Cyclopenten-1-one, 2-hydroxy-3-methyl- & 2.084 \\
16 & 20.634 & Phenol & 2.401 \\
17 & 21.289 & Phenol, 2-methoxy- & 1.561 \\
18 & 24.466 & Cyclopropyl carbinol & 2.278 \\
19 & 27.912 & 2-Propenoic acid, 3-(2-hydroxyphenyl)-, (E)- & 2.768 \\
20 & 29.473 & Phenol, 2,6-dimethoxy- & 1.535 \\
\hline & & &
\end{tabular}




\subsection{Stability characteristics of the pyrolysis oil}

The change of viscosity of pyrolysis oil at different storage conditions is presented in Figure 6. The pyrolysis oil viscosity increases with increasing storage time, due to slow polymerization and condensation reactions, the increase of viscosity of pyrolysis oil are enhanced by higher temperature, and the rate of increase of viscosity of pyrolysis oil was found to reduce after some time. This result is quite consistent with many reported results ${ }^{[25]}$. Hence though pyrolysis oil has certain instability, the instability is not too strong to use the pyrolysis oil. If in the presence of inhibitors for example hydroquinone, the rate of increase of viscosity of pyrolysis oil can dramatically reduce, due to the suppression of thermal polymerization reactions by the inhibitors $^{[26,27]}$.

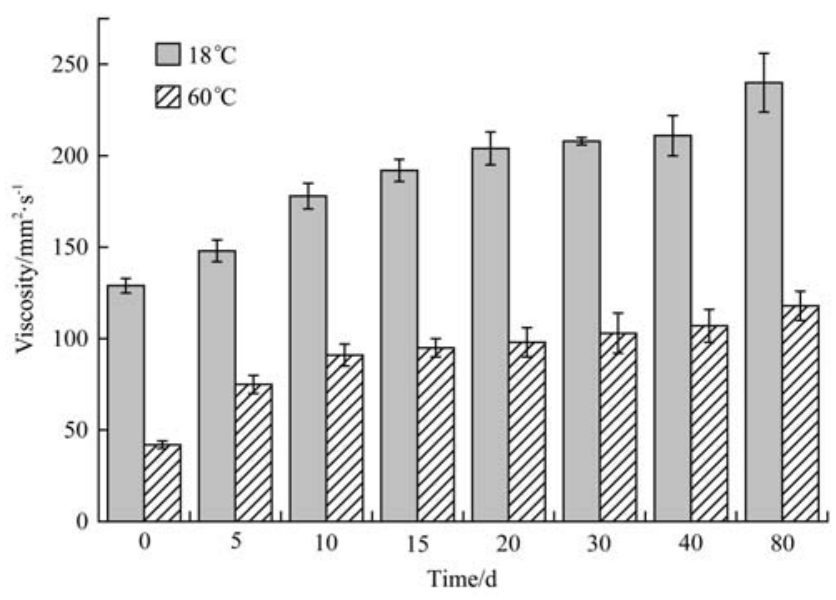

Figure 6 Viscosity variation of the pyrolysis oil with time

\section{Conclusions}

In the pyrolysis system used in this experiment, some improvements to former pyrolysis systems were done. Two screw feeders were used to prevent jamming the feeding system, and the condenser was equipped with some nozzles and a heat exchanger to cool quickly the cleaned hot gas into bio-oil. The results showed that the bio-oil yield increased with increasing pyrolysis temperature and then declined with a further increase in pyrolysis temperature. The highest bio-oil yield of $43.3 \mathrm{wt} . \%$ was obtained at $500^{\circ} \mathrm{C}$ with the dolomite as bed material. The char yield always decreased with the increase of temperature. The major chemical compounds of bio-oil included acetol, butanone, acetic acid, propionic acid, ethylene glycol, phenol, etc.
Pyrolysis oil was completely immiscible in diesel, but homogeneous emulsions were obtained when mixing the pyrolysis oil, emulsifier with diesel in different ratios.

\section{Acknowledgements}

The authors gratefully thank the support for this research from the Major State Basic Research Development Program of China (2012AA101808), National Natural Science Foundation of China (51276103 and 51206100), Shandong Provincial Natural Science Foundation, China (ZR2012EEQ018), Shandong Province Higher Educational Science and Technology Program (J12LF12) and Shandong University of Science and Technology Young Teachers Program (4072-112007).

\section{[References]}

[1] Ma L, Wang T, Liu Q, Zhang X, Ma W, Zhang Q. A review of thermal-chemical conversion of lignocellulosic biomass in China. Biotechnol Adv., 2012; 30(4): 859-873.

[2] Nakamura S, Kitano S, Yoshikawa K. Biomass gasification process with the tar removal technologies utilizing bio-oil scrubber and char bed. Applied Energy, 2016; 170: 186-192.

[3] Collard F X, Blin J. A review on pyrolysis of biomass constituents: Mechanisms and composition of the products obtained from the conversion of cellulose, hemicelluloses and lignin. Renewable and Sustainable Energy Reviews, 2014; 38: 594-608.

[4] Kan T, Strezov V, Evans T J. Lignocellulosic biomass pyrolysis: A review of product properties and effects of pyrolysis parameters. Renewable and Sustainable Energy Reviews, 2016; 57: 1126-1140.

[5] Bai X F, Zhou X Q, Li Z F, Ni J W, Bai X. Properties and applications of biochars derived from different biomass feedstock sources. Int J Agric \& Biol Eng, 2017; 10(2): 242-250.

[6] Yanik J, Kornmayer C, Saglam M, Yüksel M. Fast pyrolysis of agricultural wastes: Characterization of pyrolysis products. Fuel Processing Technology, 2007; 88(10): 942-947.

[7] Bridgwater A V. Review of fast pyrolysis of biomass and product upgrading. Biomass and Bioenergy, 2012; 38: 68-94.

[8] Yang S, Ding W, Chen H. Enzymatic hydrolysis of corn stalk in a hollow fiber ultrafiltration membrane reactor. Biomass and Bioenergy, 2009; 33(2): 332-336. 
[9] Zhao X, Luo D. Driving force of rising renewable energy in China: Environment, regulation and employment. Renewable and Sustainable Energy Reviews, 2017; 68: $48-56$.

[10] Putun A E, Apaydin E, Putun E. Rice straw as a bio-oil source via pyrolysis and steam pyrolysis. Energy, 2004; 29(12-15): 2171-2180.

[11] Zhu X F. The principle and technology of pyrolysis of biomass. The University of Science and Technology of China Press, 2006. (in Chinese)

[12] Alvarez J, Lopez G, Amutio M, Bilbao J, Olazar M. Bio-oil production from rice husk fast pyrolysis in a conical spouted bed reactor. Fuel, 2014; 128: 162-169.

[13] Pattiya A, Suttibak S. Production of bio-oil via fast pyrolysis of agricultural residues from cassava plantations in a fluidised-bed reactor with a hot vapour filtration unit. Journal of Analytical and Applied Pyrolysis, 2012; 95: 227-235.

[14] Koo W M, Jung S H, Kim J S. Production of bio-oil with low contents of copper and chlorine by fast pyrolysis of alkaline copper quaternary-treated wood in a fluidized bed reactor. Energy, 2014; 68: 555-261.

[15] Yang S I, Wu M S, Wu C Y. Application of biomass fast pyrolysis part I: Pyrolysis characteristics and products. Energy, 2014; 66: 162-171.

[16] Ngo T A, Kim J, Kim S S. Fast pyrolysis of palm kernel cake using a fluidized bed reactor: Design of experiment and characteristics of bio-oil. Journal of Industrial and Engineering Chemistry, 2013; 19(1): 137-143.

[17] Pattiya A, Sukkasi S, Goodwin V. Fast pyrolysis of sugarcane and cassava residues in a free-fall reactor. Energy, 2012; 44(1): 1067-1077.

[18] Wang S Q, Xu M L, Wang F, Li Z H. Preparation of bio-oil by catalytic pyrolysis of corn stalks using red mud. Int $\mathrm{J}$
Agric \& Biol Eng, 2016; 9(5): 177-183.

[19] Wang J, Zhong Z, Ding K, Zhang B, Deng A D, Min M, Chen P, Ruan R. Co-pyrolysis of bamboo residual with waste tire over dual catalytic stage of $\mathrm{CaO}$ and co-modified HZSM-5. Energy, 2017; 133(15): 90-98.

[20] Wang J, Zhang B, Zhong Z, Ding K, Deng A D, Min M, Chen P, Ruan R. Catalytic fast co-pyrolysis of bamboo residual and waste lubricating oil over an ex-situ dual catalytic beds of MgO and HZSM-5: Analytical PY-GC/MS study. Energy Conversion and Management, 2017; 139(1): 222-231.

[21] Wei L, Xu S, Zhang L, Zhang H, Liu C, Zhu H, Liu S. Characteristics of fast pyrolysis of biomass in a free fall reactor. Fuel Process. Technol, 2006; 87: 863-871.

[22] Xu R, Ferrante L, Briens C, Berruti F. Flash pyrolysis of grape residues into biofuel in a bubbling fluid bed. J. Anal. Appl. Pyrolysis, 2009; 86: 58-65.

[23] Luo Z, Wang S, Liao Y, Zhou J, Gu Y, Cen K. Research on biomass pyrolysis for liquid fuel. Biomass Bioenergy, 2004; 26: 455-462.

[24] Oasmaa A, Meier D. Analysis, characterization and test methods of fast pyrolysis liquids, in: A.V. Bridgwater (Ed.), Fast Pyrolysis of Biomass: A Handbook, vol. 2, CPL Press, Newbury, Berkshire, 2002; pp. 23-40.

[25] Das P, Sreelatha T, Ganesh A. Bio oil from pyrolysis of cashew nut shell-characterisation and related properties. Biomass and Bioenergy, 2004; 27(3): 265-275.

[26] Doshi V A, Vuthaluru H B, Bastow T. Investigations into the control of odour and viscosity of biomass oil derived from pyrolysis of sewage sludge. Fuel Processing Technology, 2005; 86: 885- 897.

[27] Diebold J P, Czernik S. Additives to lower and stabilize the viscosity of pyrolysis oils during storage. Energy \& Fuels, 1997; 11(5): 1081-1091. 